\title{
PENGARUH PENYULUHAN PAJAK, SURAT PEMBERITAHUAN PAJAK TERUTANG (SPPT), DAN SANKSI PAJAK TERHADAP KEPATUHAN WAJIB PAJAK BUMI DAN BANGUNAN
}

\section{THE INFLUENCE OF TAX COUNSELING, SPPT, AND TAX SANCTIONS ON LAND AND BUILDING TAXPAYER COMPLIANNCE}

\author{
S. Hambani, A. Lestari \\ Program Studi Akuntansi Fakultas Ekonomi Universitas Djuanda, Bogor \\ E-mail : susy.hambani@unida.ac.id, asihlestari480@gmail.com
}

\begin{abstract}
Taxpayer compliance is a condition where taxpayers fulfill their taxation rights and obligations. The purpose of this study was to determine the effect of tax counseling, SPPT, and tax sanctions on land and building taxpayers compliance in the Cidahu sub-district of Sukabumi district. The population in this study amounted to 24.456 taxpayers, with a total sample of 400 respondents using the slovin formula. This research design uses descriptive associative survey method, with probability sampling technique. data sources used are primary and secondary data. The tests used are validity, reliability, classic assumptions and data analysis. Simultaneously variable tax counseling, SPPT and tax sanctions have a positive significant effect on land and building taxpayers compliance. While partially tax counseling and tax sanctions have a significant positive effect on land and building taxpayers compliance, however the variable SPPT show different result, namely a significant negative effect on land and building taxpayer compliance. All these indicators become supporting factors in the study.
\end{abstract}

Keywords: Compliance, Counseling, SPPT, Sanctions Tax

\begin{abstract}
ABSTRAK
Kepatuhan wajib pajak merupakan suatu keadaan dimana wajib pajak memenuhi semua hak dan kewajiban perpajakannya. Tujuan dari penelitian ini adalah untuk mengetahui pengaruh penyuluhan pajak, SPPT, dan sanksi pajak terhadap kepatuhan wajib pajak bumi dan bangunan di Kecamatan Cidahu Kabupaten Sukabumi. Populasi dalam penelitian ini adalah sebanyak 24.456 wajib pajak, dengan jumlah sampel sebanyak 400 responden mengunakan rumus slovin. Desain penelitian ini menggunakan metode survey yang bersifat deskriptif asosiatif, dengan teknik probability sampling. Sumber data yang digunakan yaitu data primer dan sekunder. Uji yang digunakan adalah uji validitas, uji reliabilitas, asumsi klasik serta analisis data. Secara simultan variabel penyuluhan pajak, SPPT, dan sanksi pajak berpengaruh positif signifikan terhadap kepatuhan wajib pajak bumi dan bangun. Sedangkan secara parsial penyuluhan pajak dan sanksi pajak berpengaruh positif signifikan terhadap kepatuhan wajib pajak bumi dan bangunan, akan tetapi pada variabel SPPT menunjukan hasil yang berbeda, yaitu berpengaruh negatif signifikan terhadap kepatuhan wajib pajak bumi dan bangunan. Semua indikator tersebut menjadi faktor pendukung dalam penelitian.
\end{abstract}

Kata Kunci: Kepatuhan Wajib Pajak, Penyuluhan Pajak, Sanksi Pajak, SPPT 


\section{PENDAHULUAN}

Indonesia merupakan salah satu negara yang menjadikan pajak sebagai salah satu sumber pendapatan negara untuk membiayai pengeluaran pemerintah dan pembangunan nasional. Pajak dipandang sebagai bagian yang sangat penting dalam penerimaan negara dan bahkan dalam APBN pajak merupakan sumber pendapatan terbesar. Negara Indonesia sangat bergantung kepada pajak karena saat ini sekitar 70\% APBN Indonesia dibiayai oleh pajak. Pendapatan negara yang berasal dari sumber pajak meliputi berbagai sektor perpajakan diantaranya diperoleh dari PBB. Pajak Bumi dan Bangunan (PBB) adalah salah satu pajak pusat yang wewenangnya diserahkan kepada daerah. Dalam rangka peningkatan pendapatan negara, tidak hanya Direktorat Jendral Pajak saja yang berperan dalam peningkatan pendapatan negara melalui pajak yang nantinya juga akan disalurkan untuk kepentingan bersama, akan tetapi wajib pajak juga memiliki peran yang penting dalam peningkatan pendapatan pajak.

Negara-negara maju maupun berkembang diseluruh dunia memiliki masalah kepatuhan wajib pajak seperti timbulnya keinginan untuk melkukan tindakan penghindran, pengelakan, penyelundupan dan pelalaian pjak. Adanya tindakan-tindakan pelanggaran perpajakan tersebut menjadi masalah yang sangat penting karena akan menghambat penerimaan pajak negara. Kepatuhan wajb pajak yaitu suatu kedaan dimana wajib pajak memenuhi semua hak dan kewajiban perpajakannya (Arifin dan Nasution, 2017).

Pajak PBB di Kecamatan Cidahu Kabupaten Sukabumi di kelola oleh Kasi (Kepala Seksi) PBB yang kemudian data PBB tersebut di laporkan kepada Badan Pengelolaan Pendapatan Daerah (BAPPENDA) Kabupaten Sukabumi. Ketetapan dalam penerimaan PBB sebagai sumber Pendapatan Asli Daerah setiap tahunnya ditetapkan oleh Pemerintah Daerah, tetapi dalam hal realisasi penerimaan PBB terkadang jauh dibawah target yang telah ditetapkan. Seperti yang terjadi pada wilayah Kecamatan Cidahu Kabupaten Sukabumi terbukti masih banyaknya Wajib Pajak yang terlambat dalam membayar PBB. Hal ini terlihat bahwa realisasi $\mathrm{PBB}$ yang diterima setiap tahunnya tidak menentu, kadang mengalami kenaikan dan penurunan.

Tabel 1. Ketetapan dan Realisasi Penerimaan Pajak PBB di Kecamatan Cidahu Kabupaten Sukabumi mulai tahun 2014 hingga tahun 2017

\begin{tabular}{cccccr}
\hline \multirow{2}{*}{ Tahun } & \multicolumn{2}{c}{$\begin{array}{c}\text { Target } \\
\text { Ketetapan }\end{array}$} & \multicolumn{2}{c}{$\begin{array}{c}\text { Realisasi } \\
\text { Ketetapan }\end{array}$} & \multicolumn{2}{c}{ Sisa Ketetapan } \\
\cline { 2 - 6 } & Pajak & Pajak & $\%$ & Pajak & $\%$ \\
& Terutang & Terutang & & Terutang \\
\hline 2014 & 525.985 .921 & 474.890 .732 & 90,28 & 51.095 .189 & 9,72 \\
2015 & 690.795 .042 & 576.275 .233 & 83,42 & 114.519 .809 & 16,58 \\
2016 & 698.022 .385 & 465.498 .111 & 67,39 & 232.524 .274 & 32,61 \\
2017 & 724.594 .232 & 604.630 .859 & 83,85 & 119.963 .373 & 16,15 \\
\hline
\end{tabular}

Sumber : Kasi (Kepala Seksi) PBB Kecamatan Cidahu Kabupaten Sukabumi.

Berdasarkan data penerimaan PBB di wilayah Kecamatan Cidahu Kabupaten Sukabumi pada tabel 1 menunjukan bahwa penerimaan PBB dari tahun 2014 hingga tahun 2017 tidak pernah mencapai target. Pada tahun 2014 menunjukkan penerimaan PBB tertinggi, dengan ketetapan pokok PBB yang ditetapkan pemerintah daerah adalah sebesar 525.985.921, jumlah PBB yang telah direalisasikan adalah sebesar 474.890.732 menunjukkan persentase target yang tercapai adalah sebesar 90,28\%. Tetapi mulai tahun 2015 hingga tahun2017 terus mengalami penurunan penerimaan PBB terutama pada tahun 2016 yang menunjukkan penerimaan terendah.

Pada tahun 2015 penerimaan PBB mengalami penurunan persentase sebesar 6,86\% dengan persentase target yang tercapai adalah sebesar $83,42 \%$. Ketetapan pokok PBB yang ditetapkan pemerintah daerah adalah sebesar 690.795.042, jumlah yang terrealisasi PBB adalah sebesar 576.275.233.

Pada tahun 2016 menunjukkan penerimaan terendah dengan penurunan persentase sebesar $16,03 \%$ dan persentase target yang tercapai adalah sebesar 67,39\%. Ketetapan pokok PBB yang ditetapkan pemerintah daerah adalah sebesar 698.022.385, jumlah yang terrealisasi PBB adalah sebesar 465.498.111. Hal ini menunjukan bahwa pada tahun 2016 realisasi yang tercapai sangat jauh dibawah ketetapan target, artinya Kecamatan Cidahu Kabupaten Sukabumi tidak mampu mencapai target yang 
telah ditetapkan oleh pemerintah daerah. Terjadinya penurunan tercapainya target $\mathrm{PBB}$ pada tahun 2016 selain dari adanya wajib pajak yang tidak menempati objek pajaknya, serta mutasi/perpindahan objek pajak yang tidak melapor, kurangnya kesadaran dari petugas pajak terkait juga menjadi salah satu penyebab terjadinya penurunan tercapainya target pada tahun tersebut, dikarenakan pada tahun ini diadakan pemilihan umum serentak untuk lurah baru di Kecamatan Cidahu, sehingga masa PJS (Petugas Jabatan Sementara) 2015 berakhir. Akan tetapi kinerja dari lurah-lurah baru yang terpilih pada tahun 2016 ternyata kurang baik, hasil kinerjanya terlihat lebih baik pada masa PJS dibandingkan pada masa lurh-lurah baru yang terpilih. Tidak semua lurah baru kinerjanya kurang baik, namun ada beberapa lurah baru pada tahun ini yang kinerjnya kurang baik, misalnya lalainya dan kurang tegasnya lurah terhadap bawahannya sehingga bawahannya juga menjadi lalai terhadap tugasnya karena merasa tidak adanya teguran. Telatnya petugas dalam penyampaian atau pendistribusian SPPT juga berpengaruh terhadap tingkat penerimaan PBB pada tahun tersebut.

Pada tahun 2017 menunjukan kenaikan persentase sebesar $16,46 \%$ dengan persentase target yang tercapai sebesar $83,85 \%$. Ketetapan pokok PBB yang ditetapkan pemerintah daerah adalah sebesar 724.594.232, jumlah yang terrealisasi PBB adalah sebesar 604.630.859. Pada tahun 2017 penerimaan PBB di Kecamatan Cidahu Kabupaten Sukabumi menunjukan angka perbaikan dari tahun sebelumnya, namun kenaikan tersebut belum maksimal sehingga belum bisa memenuhi ketetapan target yang telah ditetapkan oleh pemerintah daerah.

Kepatuhan wajib pajak khususnya PBB diperlukan adanya penyuluhan pajak kepada msyarakat dalam rangka menciptakan dan menigkatkan kepatuhan wajib pajak, maksud dari diberikannya penyuluhan yaitu untuk memberikan penjelasan kepada masyarakat yang tujuan akhirnya sampai kepada sebuah perubahan sikap. Mengenai pedoman penyuluhan perpajakan menurut Peraturan Dirjen Pajak Nomor PER-03/PJ/2013 Pasal 1 ayat (1) adalah sebagai berikut: "Penyuluhan
Perpajakan merupakan suatu upaya dari pemerintah dalam meningkatkan kepatuhan pajak dengan cara membrikan informasi perpajakan kepada masyarrakat, pemerintah maupun non-pemerintah".

Ketetapan Surat Pemberitahuan Pajak Terutang (SPPT) memuat informasi tentang data objek/subjek pajak, berapa serta bagaimana penghitungan nilai dari objek pajak tersebut, dimana pajak tersebut dapat dibayarkan dan kapan waktu terakhir jatuh tempo pembayaran, juga menjadi faktor yang berpengaruh terhadap kepatuhun wajib pajak. SPPT adalah surat yang berisi tentang besarnya pajak terutang yang dignakan Dirjen Pajak untuk memberitahu wajib pajak (Dewi N et all, 2017).

Pendistribusian SPPT dilakukan

Pemerintah Daerah melalui Kecamatan, Kelurahan/Desa untuk sampai ketangan Wajib Pajak, serta menerima pembayaran PBB dari Wajib Pajak. Dalam rangka peningkatan kepathan wajib pajak PBB, kesesuaian data yang tercantum dalam SPPT dengan kepemilikan luas tanah dan bangunan yang sesungguhnya menjadi hal ynag sangat penting. Untuk meningkatkan realisasi penerimaan $\mathrm{PBB}$ seluruh aparat ditekankan untuk meningkatkan pelayanan kepada masyarakat terutama yang mengajukan keberatan dan keringanan pajak terhutang, atau proses pembetulan/pengurangan yang belum selesai yang dapat menghambat pada penerimaan PBB. juga diperlukannya membentuk tim penagih serta pemantauan SPPT PBB sehingga target penerimaan PBB bisa dipenuhi.

Sanksi pajak juga memiliki pengaruh teahadap kepatuhan wajib pajak. Sanksi pajak yaitu suatu tindakan hukum yang diberikan kepada wajib pajak atapun pejabat yang melkukan pelanggaran baik secara sengaja maupun karena alpa. Ada dua macam sanksi dalam Undang-Undang Perpajakan, yaitu sanksi administrasi dan pidana (Dewi dan Zulfikar, 2018). Belum adanya sanksi tegas untuk wajib pajak yang membandel cenderung pada terjadinya pelalaian pajak, penghindaran pajak, dan pelanggaran pajak lainnya sehingga menghambat pada penerimaan PBB dan tidak tercapainya target. Pengenaan sanksi pajak 
diperlukan untuk mencptakan kepatuhan wajib pajak dalam memnuhi kewajibannya dalam rangka membantu pembangunan negara.

Penelitian yang dilakukan saat ini adalah penelitian empiris, yang hanya menggunakan tiga variabel yaitu penyuluhan pajak, SPPT, dan sanksi pajak sebagai variabel yang mempengaruhi kepatuhan wajib pajak PBB. Penelitian tersebut dilakukan pada wilayah yang berada didalam ruang lingkup Kabupaten Sukabumi.

\section{PENGEMBANGAN HIPOTESIS}

1. Pengaruh Penyuluhan Pajak terhadap Kepatuhan Wajib Pajak PBB

Kusuma (2015) mengungkapkan bahwa semakin menarik penyuluhan yang diberikan petugas pajak maka akan meningkatkan kepatuhan pajak PBB. Sedangkan Warizal et al (2019) juga menyatakan bahwa penyuluhan dengan waktu yang tepat dan materi yang mudah dipahami dapat meningkatkan kepatuhan wajib pajak.

H1: penyuluhan pajak berpengaruh positif terhadap kepatuhan wajib pajak PBB.

2. Pengaruh SPPT terhadap Kepatuhan Wajib Pajak PBB

Marchori (2018) mengungkapkan bahwa semakin sesuai SPPT dengan objek pajak, maka akan semakin tinggi tingkat kepatuhan dalam membayar pajak PBB. Nafiah dan Warno (2018) menyatakan bahwa semakin baik SPPT yang dimiliki wajib pajak maka smakin tinggi pula keptuhan wajib pajak. Akan tetapi Kusuma (2018) mengungkapkan hal yang berbeda dalam penelitiannya yaitu SPPT tidak berpengaruh terhadap kepatuhan wajib pajak PBB karena penyampaian SPPT yang merupakan surat yang digunakan oleh dirgen pajak untuk memberitahukan besarnya pajak terutang yang tidak tepat waktu sampai kepada wajib pajak terkadang bisa menghambat wajib pajak yang ingin membayar pajak.

H2: SPPT berpengaruh positif terhadap Kepatuhan Wajib Pajak PBB.

3. Pengaruh Sanksi Pajak terhadap Kepatuhan Wajib Pajak PBB

Septarini

(2015)mengemukakan bahwa terdapat pengaruh tingkat kepatuhan wajib pajak di negara-negara Anglo-Saxon yang dipilih terhadap kehadiran sanksi pidana yang merupakan bagian dari sanksi perpajakan. Ciri umum kebijakan perpajakan adalah adanya rezim hukum formal untuk pelanggaran perpajakan. Sedangkan (Yakin dan Amrulloh, 2018). menyatakan bahwa kepatuhan perpajakan salah satunya ditantukan oleh sanksi perpajakan, semakin baik sanksi perpajakan maka akan semakin tinggi atau baik pula kepatuhan perpajakan yang dimiliki wajib pajak. Akan tetapi berbeda dengan hasil penelitian yang dilakukan oleh Dewi et al (2015), Kusuma (2015), dan Marchori (2018) yang menunjukan bahwa sanksi pajak berpengaruh negatif terhadap kepatuhan wajib pajak.

H3: Sanksi pajak berpengaruh positif terhadap Kepatuhan Wajib Pajak PBB.

\section{METODE PENELITIAN}

Penelitian ini meneliti tentang penyuluhan pajak, SPPT dan sanksi pajak terhadap kepatuhan wajib pajak PBB. Penelitian ini merupakan penelitian kuantitatif. Metode dalam Penelitian ini dikategorikan penelitian survei yang bersifat deskriptif, dengan teknik asosiatif kausal, yaitu dengan cara menguji hipotesis hubungan variabel sebanyak dua atau lebih yang mengandung sebab akibat dan biasanya diawali dengan faktor determinan.

Tabel 2. Tabel Operasionalisasi Variabel

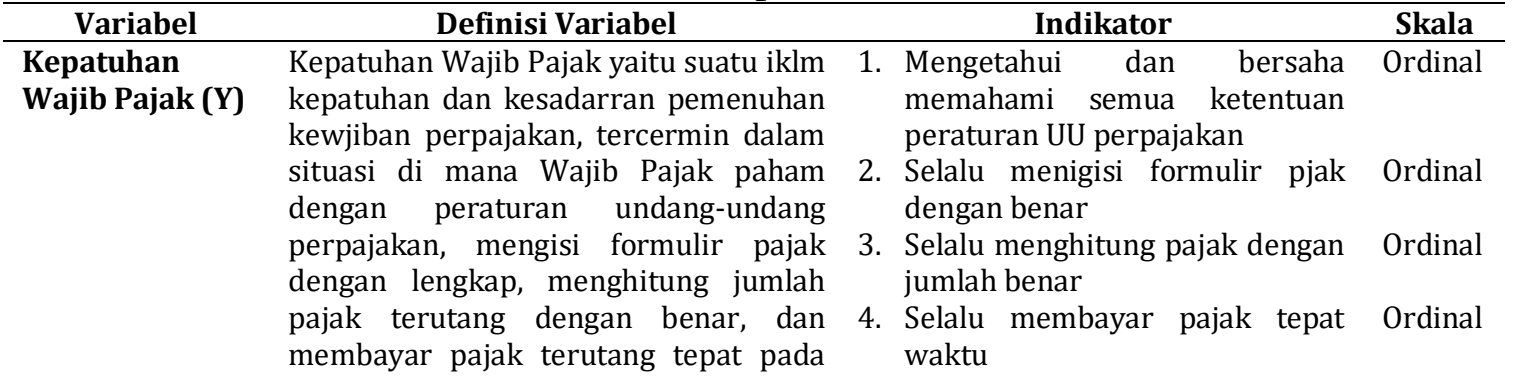


waktunya.

(M.Zain : 2007)

\begin{tabular}{|c|c|c|c|}
\hline & $\begin{array}{ll}\text { Penyuluhan } & \text { Penyuluhan Perpajakan yaitu suatu } \\
\text { Pajak }\left(\mathbf{X}_{1}\right) & \text { upaya dari pemerintah dalam } \\
& \text { meningkatkan kepatuhan pajak dengan } \\
& \text { cara memberkan informasi perpajakan } \\
& \text { kepada masyarrakat, pemerintah } \\
& \text { maupun non-pemerintah. } \\
& \text { (Dirjen Pajak Nomor PER-03/PJ/2013) }\end{array}$ & $\begin{array}{l}\text { 1. Waktu penyuluhan } \\
\text { 2. Materi penyuluhan } \\
\text { 3. Pemahaman materi penyuluhan } \\
\text { 4. Cara petugas pajak dalam } \\
\text { menyampaikan } \\
\text { penyuluhan materi } \\
\text { 5. Keikutsertaan Wajib Pajak } \\
\text { dalam penyuluhan. }\end{array}$ & $\begin{array}{l}\text { Ordinal } \\
\text { Ordinal } \\
\text { Ordinal } \\
\text { Ordinal }\end{array}$ \\
\hline $\begin{array}{l}\text { Surat } \\
\text { Pemberitahuan } \\
\text { Pajak Terutang } \\
\text { (SPPT) }\left(\mathrm{X}_{2}\right)\end{array}$ & \begin{tabular}{lccr} 
SPPT yaitu & \multicolumn{3}{l}{ surat yang berisi tentang } \\
besarnya & pajak & terutang & yang \\
digunakan & Dirjen & Pajak & untuk \\
memberitahu & wajib & pajak & (Suandy \\
2005:56). & & &
\end{tabular} & $\begin{array}{l}\text { 1. Penetapan NJOP tanah dan } \\
\text { bangnan } \\
\text { 2. Penetapan luas tanah dan } \\
\text { bangunan } \\
\text { 3. Penetpan kelas tanah dan } \\
\text { bangnan } \\
\text { 4. Tanggal jatuh tempo yang } \\
\text { tertera di SPPT } \\
\text { 5. Tempat atau lokasi pembayrran } \\
\text { pajak. }\end{array}$ & Ordinal \\
\hline $\begin{array}{l}\text { Sanksi } \\
\left(\mathrm{X}_{3}\right)\end{array}$ & $\begin{array}{l}\text { Sanksi pajak adalah jaminan bahwa } \\
\text { ketentuan UU atau norma perpajkan } \\
\text { akan dituruti/ditaati/dipatuhi. Sanksi } \\
\text { pajak merupakan upaya pemerintah } \\
\text { sebagai alat pencegah (preventif) agar } \\
\text { wajb pajak tidak melangagar norma } \\
\text { perpajakan. } \\
\text { (Mardiasmo: 2009) }\end{array}$ & $\begin{array}{l}\text { 1. Tanggapan WP trhadap sanksi } \\
\text { perpajakan } \\
\text { 2. Besar kecilnya sanksi yang } \\
\text { dikenakkan sesuai dengan } \\
\text { pelanggran yang dilakukan } \\
\text { 3. Sanksi yang tegas diberlikan } \\
\text { kepada semua WP yang } \\
\text { melakukan pelnggaran } \\
\text { 4. Denda yang diberkan tidak } \\
\text { memberatkan Wajib Pajak } \\
\text { 5. Tidak adanya hukuman yang } \\
\text { diberikn akibat melakukan } \\
\text { pembyaran melebihi tanggal } \\
\text { jatuh tempo }\end{array}$ & $\begin{array}{l}\text { Ordinal } \\
\text { Ordinal }\end{array}$ \\
\hline
\end{tabular}

\section{Pengujian Validitas}

Sugiyono (2015) Item instrumen dianggap valid jika koefisien sama dengan atau lebih besar dari 0,3, jika kurang dari 0,3 maka item instrumen tersebut dinyataakan tidak valid.

\begin{tabular}{cc}
\multicolumn{2}{c}{ Tabel 3. Kriteria Uji Validitas } \\
\hline $\begin{array}{c}\text { Corrected Item Total } \\
\text { Corelation }\end{array}$ & Keterangan \\
\hline$\geq 0,3$ & Valid \\
$<0,3$ & Tidak Valid \\
\hline
\end{tabular}

\section{Pengujian Reliabilitas}

Rahajeng (2017) realiabilitas merupakan alat untuk mengukur kuesioner yang merrupakan indiktor dari suatu variabel. Sedangkan untuk mengukur koefisien keandalan (reability) kuesioner, digunakan rumus Cronbach Alpha sebagai berikut :

Tabel 4. Kriteria Uji Reliabilitas

\begin{tabular}{cc}
\hline Alpha Cronbach & Keterangan \\
\hline$\geq 0,6$ & Reliabel \\
$<\mathbf{0 , 6}$ & Tidak Reliabel \\
\hline
\end{tabular}

Sumber : Sugiyono, 2007

\section{Uji Asumsi Klasik}

Metode regresi berganda yang dapat dilakukan dalam pengujian ini harus terhindar dari kemungkinan terjadinya penyimpangan asumsi klasik tersebut. Persamaan regresi dapat diakatakan baik untuk menggambarkan hubungan fungsional kelompok variabel tidak bebas jika persamaan tersebut memenuhi asumsi-asumsi regresi. Untuk melakukan uji asumsi klasik atas data primer ini, maka dalam penelitian ini dilakukan uji normalitas, uji multikolonieritas, dan uji heteroskedastisitas.

\section{Metode Analisis Data}

Analisis Regresi Linear Berganda digunakn untuk mernaksir bagaimana keadaan (naik-turunnya) variabel dependen bila dua atau lebih varibel dependen sebagi faktor 
prredictor dimanipulasi (dinaik turunkan misalnya) Sugiyono (2015). Bentuk persamaan regresi yang dirumuskan berdasarkan hipotesis yang dikembangkan adalah sebagai berikut (Nugroho, 2011: 92) :

$$
\mathrm{Y}=\alpha+\beta_{1} \mathrm{X}_{1}+\beta_{2} \mathrm{X}_{2}+\beta_{3} \mathrm{X}_{3} \varepsilon
$$

Keterangan :

$\mathrm{Y} \quad=$ Kepatuhan Wajib Pajak

$\alpha \quad=$ Konstanta

$\beta \quad=$ Koefisien regresi

$\mathrm{X}_{1} \quad=$ Koefesien regresi Penyuluhan Pajak

$\mathrm{X}_{2}=$ Koefesien regresi Surat

Pemberitahuan

Pajak

Terutang (SPPT)

$X_{3}=$ Koefesien regresi Sanksi Pajak

$\varepsilon \quad=$ Eror

\section{Koefisien Korelasi Berganda}

Koefisien korelasi merupakan angka yang menunjukan arah dan kuatnya hubungan antara variabel indpenden dengan varibel dependen. Adapun rumus yang digunakan menurut Sugiyono (2015) adalah sebagai berikut:

$$
r X i Y=\frac{n \Sigma X i Y-(\Sigma X i)(\Sigma Y)}{\sqrt{\left\{n \Sigma X i^{2}-\left(\Sigma X i^{2}\right)\right\}\left\{n \Sigma Y^{2}-(\Sigma Y)\right\}}}
$$

Keterangan :

$\mathrm{r} \quad=$ Koefisien Korelasi

$X_{i} \quad=X_{1 \text { dan }} X_{2}, X_{3}$

$Y \quad=$ Kepatuhan Wajib Pajak Bumi dan

Bangunan (Y)

$n \quad=$ Banyaknya sampel

$i \quad=1,2,3$

\section{Koefisien Determinasi $\left(\mathbf{R}^{\mathbf{2}}\right)$}

Sugiyono (2015) menyatakan bahwa koefisien determinasi (R Square/ $\mathrm{R}^{2}$ ) digunakan untuk mengetaui presentase kontribusi pengaruh variable independen secara bersama-sama terhadap variabel dependen.

$$
\mathrm{KD}=\mathrm{r}^{2} \times 100 \%
$$

Keterangan:

$\mathrm{KD}=$ Koefisien Determinasi

$r^{2} \quad=$ Koefisien Korelasi

\section{Uji Hipotesis}

\section{Uji Simultan $($-test $)$}

Priyatno (2013:48) menyatakan bahwa uji statistik $F$ atau ujian koefisien regresi secara serentak, yaitu digunakan untuk mengetahui apakah semua variabel independen (Pengetahuan Penyuluhan Pajak, SPPT, dan Sanksi Pajak) yang dimasukan dalam model mempunyai pengaruh secara serentak terhadap variabel dependen (Kepatuhan Wajib Pajak PBB).

\section{Uji Parsial (t-test)}

Septarini (2015) menyatakan bahwa uji $\mathrm{t}$ dimaksudkan untuk mengetahui pengaruh variabel independen (Penyuluhan Pajak, SPPT, dan Sanksi Pajak) terhadap variabel dependen (Kepatuhan Wajib Pajak PBB) secara individual atau secara parsial.

\section{HASIL DAN PEMBAHASAN Uji Validitas}

Uji validitas bertujuan untuk mengtahui sejauh mana ketepatan alat ukur atau instrumen yang digunakan dapat menngukur apa yang seharusnya diukur. Uji validitas dilakukan dengan menghitung korelasi antar masing-masing butir-butir penyataan dengan skor total pada masing-masing variabel. Nilai tersebut kemudian dibandingkan dngan nilai $\mathrm{r}_{\text {Kritis }}$. Hasil uji validitas variabel Penyuluhan Pajak $\left(X_{1}\right)$, SPPT $\left(X_{2}\right)$, Sanksi Pajak $\left(X_{3}\right)$ dan variabel kepatuhan wajib pajak PBB (Y).

Tabel 5. Hasil Uji Validitas

\begin{tabular}{llccc}
\hline No & \multicolumn{1}{c}{ Variabel } & $\mathbf{r}_{\text {hitung }}$ & $\mathbf{r}_{\text {kritis }}$ & Keterangan \\
\hline 1. & Penyuluhan Pajak & 0,773 & 0,3 & Valid \\
& (X1) & & & \\
2. & SPPT (X2) & 0,649 & 0,3 & Valid \\
3. & $\begin{array}{l}\text { Sanksi Pajak (X3) } \\
\text { Kepatuhan Wajib }\end{array}$ & 0,656 & 0,3 & Valid \\
4. & Pajak PBB (Y) & 0,656 & 0,3 & Valid \\
\hline
\end{tabular}

Sumber: Output pengelolaan data dengan SPSS 20, diolah kembali 2018

Berdasarkan tabel 11 tersebut menunjukan bahwa dilihat dari skor rata-rata variabel penyuluhan pajak yaitu sebesar 0,773 , variabel SPPT sebesar 0,649, variabel sanksi pajak sebesar 0,656, dan kepatuhan wajib pajak PBB sebesar 0,656, semuanya menunjukan nilai hitung yang lebih dari 0,3 sehingga dapat dinyatakan bahwa semua instrumen yang digunakan valid, dan layak digunakan.

\section{Uji Reliabilitas}

Uji reliabilitas digunakan untuk menngetahui seberapa jauh konsistensi dan keterpercayaan atas hasil jawaban responden terhadap instrumen/pernyataan yang diberikan. Untuk mengukur konsistensi intrval 
penggunan instrumen digunakan Cronbach Alpha, untuk mengetahui bahwa semua variabel dikatakan reliabel, rata-rata nilai Cronbach Alpha harus lebih besar dari atau sama dengan 0,6.

Tabel 6. Hasil Uji Reliabilitas

\begin{tabular}{|c|c|c|c|c|}
\hline No & Variabel & $\begin{array}{c}\text { Cronbach's } \\
\text { Alpha Item- } \\
\text { Total } \\
\text { Correlation }\end{array}$ & $\mathbf{R}_{\text {kritis }}$ & Kesimpulan \\
\hline 1. & $\begin{array}{l}\text { Penyuluhan } \\
\text { Pajak (X1) }\end{array}$ & 0,834 & 0,6 & Reliabel \\
\hline 2. & SPPT (X2) & 0,728 & 0,6 & Reliabel \\
\hline 3. & $\begin{array}{l}\text { Sanksi Pajak } \\
\text { (X3) }\end{array}$ & 0,738 & 0,6 & Reliabel \\
\hline 4. & $\begin{array}{l}\text { Kepatuhan } \\
\text { Wajib Pajak } \\
\text { PBB (Y) }\end{array}$ & 0,747 & 0,6 & Reliabel \\
\hline
\end{tabular}

Sumber: Output pengelolaan data dengan SPSS 20, diolah kembali 2018.

Berdasarkan tabel 6 tersebut, rekapitulasi uji reliabilitas dari setiap rata-rata item pernyataan variabel penyuluhan pajak sebesar 0,834, SPPT sebesar 0,728, sanksi pajak sebesar 0,738 dan kepatuhan wajib pajak PBB sebesar 0,747 , semua nilai tersebut menunjukan lebih besar dari 0,6 sehinga semua instrumen yang digunakan dapat dikatakan reliabel, dan layak digunakan.

\section{Uji Asumsi Klasik}

\section{Uji Normalitas}

1. Metode Statistika One Sample KolmogorovSmirnov

Tabel 7.One-Sample KolmogorovSmirnov Test

\begin{tabular}{llr}
\hline & & $\begin{array}{c}\text { Unstandardized } \\
\text { Residual }\end{array}$ \\
\hline $\mathrm{N}$ & Mean & 400 \\
Normal Parameters,$b$ & Std. & $0 \mathrm{E}-7$ \\
& Deviation & 1,25754802 \\
& Absolute &, 045 \\
Most Extreme Differences & Positive &, 045 \\
& Negative &,- 037 \\
Kolmogorov-Smirnov Z & &, 896 \\
Asymp. Sig. (2-tailed) & &, 398 \\
\hline Sumber: Output pengolahan data dengan SPSS 20, 2018
\end{tabular}

Berdasarkan hasil pengujian one sample Kolmogorov-Smirnov (K-S) nilai Asymp. Sig. (2-tailed) yaitu sebesar 0,398. Hal tersebut menunjukan bahwa data telah terdistribusi normal karena nilai Asymp. Sig. (2-tailed) lebih besar dari 0,05 .

\section{Uji Multikolonieritas}

Tabel 8. Uji Multikolonieritas Coefficients ${ }^{a}$

\begin{tabular}{|c|c|c|c|c|c|c|c|}
\hline \multirow[t]{2}{*}{ Model } & \multicolumn{2}{|c|}{$\begin{array}{c}\text { Unstandardi } \\
\text { zed } \\
\text { Coefficients }\end{array}$} & \multirow{2}{*}{\begin{tabular}{|c|}
$\begin{array}{c}\text { Stan } \\
\text { dardi }\end{array}$ \\
zed \\
Coeff \\
icien \\
ts \\
Beta \\
\end{tabular}} & \multirow[t]{2}{*}{$\mathbf{T}$} & \multirow[t]{2}{*}{ Sig. } & \multicolumn{2}{|c|}{$\begin{array}{c}\text { Collinearity } \\
\text { Statistics }\end{array}$} \\
\hline & B & $\begin{array}{c}\text { Std. } \\
\text { Error }\end{array}$ & & & & $\begin{array}{l}\text { Tol } \\
\text { era } \\
\text { nce } \\
\end{array}$ & VIF \\
\hline (Constant) & 5,846 & 1,583 & & 3,693 & ,000 & & \\
\hline $\begin{array}{l}\text { Penyuluhan } \\
\text { Pajak }\end{array}$ & ,942 & ,069 & ,672 & 13,709 & ,000 & ,626 & 1,597 \\
\hline SPPT &,- 204 &, 056 &,- 174 & $-3,620$ & ,000 & ,649 & 1,541 \\
\hline $\begin{array}{l}\text { Sanksi } \\
\text { Pajak }\end{array}$ & ,170 & ,047 & ,146 & 3,654 & ,000 & ,938 & 1,066 \\
\hline
\end{tabular}

Berdasarkan tabel 14, terlihat bahwa tiga variabel bebas memiliki nilai VIF penyuluhan pajak sejumlah 1,597 , sedangkan nilai tolerance variabel penyuluhan pajak 0,626. Nilai VIF SPPT 1,541, nilai tolerance SPPT 0,649 dan untuk nilai VIF sanksi pajak 1,066, sedangkan untuk nilai tolerance sanksi pajak 0,938. Ketiga variabel tersebut memiliki nilai VIF kurang dari $10(\mathrm{VIF}<10)$ dan memiliki nilai tolernce > dari 0,1, maka dapat disimpulukan bahwa model regresi tidak terjadi gejala multikolineriaritas.

\section{Uji Heteroskedastisitas}

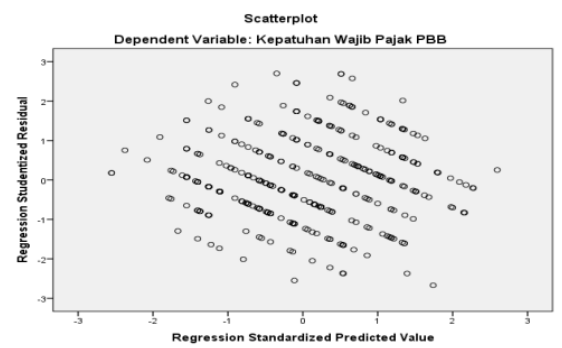

Sumber: Output pengolahan data dengan SPSS 20, 2018 Grafik Scatterplot

Berdasarkan gambar grafik scatterplot dapat terlihat bahwa titik titik menybar secara acak, tidak membentuk sebuah pola tertentu yang jelas, serta tersebar baik diatas maupun dibawah angka 0 pada sumbu Y. Hal tersebut menunjukan bahwa tidak terjadi heterskedastisitas pada model regresi, sehingga model regresi tersebut layak digunakan untuk memprediksi kepatuhan 
wajib pajak PBB berdasarkan masukan variabel penyuluhan pajak, SPPT dan sanksi pajak.

\section{Metode Analisis Data}

\section{Analisa Regresi Berganda}

Analisisis regresi linear berganda digunkan untuk mengetahui hubungan fungsional antara beberapa variabel bebas secara bersama-sama terhadap variabel terikat, dan juga untuk mengetahui jika nilai variabel indpenden dinaikkan atau diturunkan nilainya.

Tabel 9. Analisis Regresi Linier Berganda Coefficients ${ }^{a}$

\begin{tabular}{l|r|r|r|r|r}
\hline Model & \multicolumn{2}{|c|}{$\begin{array}{c}\text { Unstandardized } \\
\text { Coefficients }\end{array}$} & $\begin{array}{c}\text { Standa } \\
\text { rdized } \\
\text { Coeffic } \\
\text { ients }\end{array}$ & \multirow{2}{*}{ T } & Sig. \\
\cline { 2 - 4 } & \multicolumn{1}{|c|}{$\begin{array}{c}\text { Std. } \\
\text { Error }\end{array}$} & Beta & & \\
\hline (Constant) & 5,846 & 1,583 & & 3,693 &, 000 \\
Penyuluhan &, 942 &, 069 &, 672 & 13,709 &, 000 \\
Pajak & & & & & \\
SPPT &,- 204 &, 056 &,- 174 & $-3,620$ &, 000 \\
Sanksi Pajak &, 170 &, 047 &, 146 & 3,654 &, 000 \\
\hline
\end{tabular}

a. Dependent Variable: Kepatuhan Wajib Pajak PBB

Sumber: Output pengolahan data dengan SPSS 20, 2018

Berdasarkan Tabel 15 diketahui bahwa nilai persamaan regresi yaitu sebagai berikut :

$$
\begin{gathered}
\mathrm{Y}=\alpha+\beta_{1} X_{1}+\beta_{2} X_{2}+\beta_{3} X_{3}+\varepsilon \\
\gamma=5.846+0,942 X^{1}-0,204 X^{2}+0,170 X^{3}+\varepsilon
\end{gathered}
$$

Interprestasi dari regresi tersebut adalah sebagai berikut :

1. Hasil persamaan regresi tersebut diperoleh nilai konstanta sebesar 5,846 nilai tersebut mempunyai arti bahwa jika semua variabel bebas yaitu penyuluhan pajak, SPPT dan sanksi pajak bernilai nol (0), maka nilai variabel terikat (Beta) Kepatuhan Wajib Pajak PBB bernilai 5,846 atau nilai kepatuhan wajib pajak PBB adalah tetap.

2. Hasil persamaan regresi untuk variabel Penyuluhan Pajak diperoleh nilai koefisien sebesar 0,942. Hal tersebut menunjukan bahwa untuk setiap peningkatan penyuluhan pajak sebesar satu satuan, dengan asumsi variabel SPPT dan sanksi pajak bernilai nol (0), maka menyebabkan meningkatnya variabel (Beta) kepatuhan wajib pajak PBB sebesar 0,942 .
3. Hasil persamaan regresi untuk variabel SPPT diperoleh nilai koefisien sebesar 0,204 ini menunjukan bahwa SPPT berlawanan arah dengan resiko sistematis. Hal tersebut mengandung arti bahwa untuk setiap peningkatan SPPT sebesar satu satuan, dengan asumsi variabel penyuluhan pajak dan sanksi pajak bernilai nol (0), maka menyebabkan menenurunnya variabel (Beta) kepatuhan wajib pajak PBB sebesar -0,204.

4. Hasil persamaan regresi untuk variabel Sanksi Pajak diperoleh nilai koefisien sebesar 0,170. Hal tersebut menunjukan bahwa untuk setiap peningkatan Sanksi Pajak sebesar satu satuan, dengan asumsi variabel penyuluhan pajak dan SPPT bernilai nol (0), maka menyebabkan meningkatnya variabel (Beta) kepatuhan wajib pajak PBB sebesar 0,170.

\section{Koefesien Korelasi Berganda}

Analisis koefisien korelasi ganda digunakan untuk mengatahui derajat kekuatan hubungan antara variabel bebas secara bersama-sama terehadap keptuhan wajib pajak PBB.

Tabel 10. Koefesien Kolerasi Berganda

\begin{tabular}{|c|c|c|c|c|}
\hline \multicolumn{5}{|c|}{ Model Summaryb } \\
\hline Model & $\mathbf{R}$ & $\begin{array}{c}\mathbf{R} \\
\text { Square }\end{array}$ & $\begin{array}{l}\text { Adjusted } \\
\text { R Square }\end{array}$ & $\begin{array}{l}\text { Std. Error of the } \\
\text { Estimate }\end{array}$ \\
\hline 1 & 36 & ,405 & ,400 & 1,394 \\
\hline
\end{tabular}
Model Summaryb

Sumber: Output pengolahan data dengan SPSS 20, 2018

\section{Koefisien Determinasi}

Koefesien determinasi dilakukan untuk mengetahui besarnya kontribusi variabel bebas terhadap kepatuhan wajib pajak PBB.

Tabel 11. Koefisien Determinasi Model Summaryb

\begin{tabular}{c|c|c|c|c}
\hline Model & $\mathbf{R}$ & R Square & $\begin{array}{c}\text { Adjusted } \\
\text { R Square }\end{array}$ & $\begin{array}{c}\text { Std. Error of } \\
\text { the Estimate }\end{array}$ \\
\hline $1 \quad, 636^{\mathrm{a}}$ &, 405 &, 400 & 1,394
\end{tabular}

a. Predictors: (Constant), Sanksi Pajak, SPPT, Penyuluhan Pajak

b. Dependent Variable: Kepatuhan Wajib Pajak PBB

Sumber: Output pengolahan data dengan SPSS 20, 2018

Berdasarkan tabel 11 diatas, diperoleh angka $\mathrm{R}^{2}$ ( $R$ squer) sebesar 0,405 atau $(40,5 \%)$. Hal ini menunjukan bahwa kontribusi variabel bebas terahadap Kepatuhan Wajb Pajak PBB sebesar 40,5\%, sedangkan sisanya $59,5 \%$ dipengarhi atau dijelaskan oleh varibel lain 
yang tidak dimasukann dalam model penelitian ini.

\section{Pengujian Hipotesis}

\section{Uji F-test}

\begin{tabular}{lccccc}
\multicolumn{6}{c}{ Tabel 12. Uji F } \\
\multicolumn{6}{c}{ ANOVA $^{\mathbf{a}}$} \\
\hline Model & $\begin{array}{c}\text { Sum of } \\
\text { Squares }\end{array}$ & Df & $\begin{array}{c}\text { Mean } \\
\text { Square }\end{array}$ & F & Sig. \\
\hline Regression & 523,565 & 3 & 174,522 & $89,773.000^{\mathrm{b}}$ \\
Residual & 769,833 & 396 & 1,944 & & \\
Total & 1293,398 & 399 & & & \\
\hline
\end{tabular}

a. Dependent Variable: Kepatuhan Wajib Pajak PBB

b. Predictors: (Constant), Sanksi Pajak, SPPT, Penyuluhan Pajak

Sumber: Output pengolahan data dengan SPSS 20, 2018

Berdasarkan tabel 18 diperoleh nilai $f_{\text {hitung }}$ sebesar 89,773, sedangkan $f_{\text {tabel }}$ sebesar 3,39, maka Apabila $f_{\text {hitung }}$ dibandingkan dengan $f_{\text {tabel }}$ maka $f_{\text {hitung }}>f_{\text {tabel }}(89,773>3,39)$ dengan tingkat signifikansi sebesar $0,000<$ 0,05. Berarti Ho ditolak dan Ha diterima, maka dapat disimpulkan bahwa Penyuluhan Pajak, SPPT dan Sanksi Pajak secara simultan berpengaruh signfikan terhadap Kepatuhan Wajib Pajak PBB.

\section{Uji t-test}

Berdasarkan perhitungan diperoleh hasil berikut ini :

\section{Tabel 13. Uji t}

Coefficients

\begin{tabular}{l|r|r|r|r|r}
\hline Model & \multicolumn{2}{|c|}{$\begin{array}{c}\text { Unstandardiz } \\
\text { ed } \\
\text { Coefficients }\end{array}$} & $\begin{array}{c}\text { Standar } \\
\text { dized } \\
\text { Coefficie } \\
\text { nts }\end{array}$ & \multirow{2}{*}{ T } & Sig. \\
\cline { 2 - 4 } & $\mathbf{B}$ & $\begin{array}{c}\text { Std. } \\
\text { Error }\end{array}$ & Beta & & \\
\hline (Constant) & 5,846 & 1,583 & & 3,693 &, 000 \\
Penyuluhan &, 942 &, 069 &, 672 & 13,709 &, 000 \\
Pajak &, 204 &, 056 &,- 174 & $-3,620$ &, 000 \\
SPPT &,- 204 &, 047 &, 146 & 3,654 &, 000 \\
Sanksi Pajak &, 170 &, 04 &
\end{tabular}

a. Dependent Variable: Kepatuhan Wajib Pajak PBB

Sumber: Output pengolahan data dengan SPSS 20, 2018

1. Hasil pengujian dengan menggunakan uji t diperoleh nilai untuk penyuluhan pajak sebesar 13,709. Apabila $t_{\text {hitung }}$ dibandingkan dengan $t_{\text {tabel }}$ maka $t_{\text {hitung }}$ $>t_{\text {tabel }}(13,709>1,965)$ dengan tingkat signifikansi sebesar $0,000<0,05$ dan nilai koefisien regresi (B) bernilai positif. Kondisi ini bermakna bahwa secara parsial penyuluhan pajak berpengaruh positif dan signifikan terhadap kepatuhan wajib pajak PBB. Sehingga dapat disimpulkan hipotesis pertama atau $\left(\mathrm{H}_{1}\right)$ diterima.

2. Hasil pengujian diperoleh nilai untuk SPPT sebesar -3,620. Apabila $t_{\text {hitung }}$ dibandingkan dengan $t_{\text {tabel }}$ maka $t_{\text {hitung }}$ $>t_{\text {tabel }}(-3,620>1,965)$ dengan tingkat signifikansi sebesar $0,000<0,05$ dan nilai koefisien regresi (B) bernilai negatif. Kondisi ini bermakna bahwa secara parsial SPPT berpengaruh negatif dan signifikan terhadap kepatuhan wajib pajak bumi dan bangunan. Nilai $\mathrm{t}$ negatif menunjukan bahwa SPPT mempunyai hubungan yang berlawanan arah dengan kepatuhan wajib pajak PBB. Petugas pajak telat dalam mendistribusikan SPPT menyebabkan terjadinya penunggakan pajak/telat bayar pajak dari masyarakat atau wajib pajak menjadi faktor penyebab variabel SPPT berpengaruh negatif dan signifikan. Sehingga dapat disimpulkan hipotesis kedua atau $\left(\mathrm{H}_{2}\right)$ ditolak.

3. Hasil pengujian diperoleh nilai untuk Sanksi Pajak sebesar 3,654. Apabila $t_{\text {hitung }}$ dibandingkan dengan $t_{\text {tabel }}$ maka $t_{\text {hitung }}>t_{\text {tabel }}(3,654>1,965)$ dengan tingkat signifikansi sebesar $0,000<0,05$. dan nilai koefisien regresi (B) bernilai positif. Kondisi ini bermakna bahwa secara parsial sanksi pajak bepengaruh positif dan signifikan terhadap kepatuahan wajib pajak PBB. Sehingga dapat disimuplkan hipotesis ketiga atau $\left(\mathrm{H}_{3}\right)$ diterima.

\section{Pembahasan}

\section{Uji F}

Pengaruh Penyuluhan Pajak, SPPT dan Sanksi Pajak terhadap Kepatuhan Wajib Pajak PBB pada Kecamatan Cidahu Kabupaten Sukabumi menunjukan bahwa kepatuhan PBB dapat diukur dari sejauh mana penerapan Penyuluhan Pajak, SPPT dan Sanksi Pajak yang dijalankan. Penyuluhan Pajak, SPPT dan Sanksi Pajak yang baik dan efektif akan meningkatkan tingkat Kepatuhan Wajib Pajak. Dari hasil pengujian diperoleh $f_{\text {hitung }}>f_{\text {tabel }}$ $(89,773>3,39)$ dengan tingkat signifikansi sebesar $0,000<0,05$. Berarti Ho ditolak dan Ha diterima. Penyuluhan Pajak, SPPT dan Sanksi Pajak secara bersama-sama menghasilkan angka yang positif, maka dapat 
disimpulkan bahwa Penyuluhan Pajak, SPPT dan Sanksi Pajak secara simultan berpengaruh signifikan terhadap Kepatuhan Wajib Pajak PBB di Kecamatan Cidahu Kabupaten Sukabumi.

\section{Uji t}

\section{Pengaruh Penyuluhan Pajak}

Hasil pengujin hipotesis pertama diperoleh bahwa secara parsial (individu) terdapat pengruh yang positif dan signfikan antara Penyuluhan Pajak (X1) terhadap Kepatuhann Wajib Pajak PBB (Y) dngan nilai koefisien rgresi sebesar 0,942 dan nilai signifikansi 0,000. Hal ini mengindikasikan bahwa pemberian materi Penyuluhan Pajak dari petugas pajak dapat meningkatkan Kepatuhan Wajib Pajak. Sehingga, semakin baik dan menarik penyuluhan yang diberikan oleh petugas pajak maka smakin tinggi pula kepaturahan Wajib Pajak dlam membayar PBB. Hal ini sejlan dengan pennelitian yang dilakukan oleh (Dewi dan Zulfikar, 2018). menunjukan bahwa penyuluhan memiliki pengaruh yang positif dan signifikan terhadap Kepatuhan Wajib Pajak.

\section{Pengaruh Surat Pemberitahuan Pajak Terutang}

Hasil pengujian hipotesis ke dua diperoleh bahwa secara parsial (individu) terdapat pengaruh yang negatif dan signifikan antara SPPT (X2) terhadap Kepatuhan Wajib Pajak (Y) dengan nilai kofisien regresi -0,204 dan nilai signifikansi 0,000. Hal ini menigindikasikan bahwa ada pengaruh antara SPPT dengan Kepatuhan Wajib Pajak PBB. Pada penelitian ini, untuk variabel SPPT ditemukan hasil yang berbeda dengan peneliti terdahulu yang dilakukan oleh Setyowati, dan Yushita (2017). yang dalam penelitiannya menunjukan hasil bahwa SPPT memliki pengaruh yang positf dan signifikan terahadap Kepatuhn Wajib Pajak. Sedangkan dalam penelitian ini variabel SPPT berpengaruh negatif dan signifikan, karena petugas pajak telat dalam mendistribusikan SPPT menyebabkan terjadinya penunggakan pajak/telat bayar pajak dari masyarakat atau Wajib Pajak (WP) menjadi faktor penyebab variabel SPPT berpengaruh negatif dan signifikan.

\section{Pengaruh Sanksi Pajak}

Hasil pengujian hipotesis ke tiga diperoleh bahwa secara parsial (individu) terdapat penagruh yang positif dan siginifikan antara Sanksi Pajak (X3) terhadap Kpatuhan Wajib Pajak (Y) denagan nilai koefisien regresi 0,170 dan signifikansi 0,000. Hal ini menunjukan bahwa Sanksi Pajak memliki pengaruh yng positif dan signfikan terhadap Kepatuhan Wajib Pajak PBB, serta mengindikasikan bahwa sanksi pajak yang jelas dan tegas nampaknya diperlukan dalam mningkatkan kepatuhan wajb pajak PBB, dimana pemberian sanksi sanksi baik materi (apabila berupa denda) waktu dan nama baik (apabila pidana) akan memberikan efek jera pada Wajib Pajak yang melalaikan kewajiban perpajakannya, sehingga wajib pajak akan berfikir dua kali sebelum melakukan pelanggaran yang akan merugikan dirinya. Hal ini sejalan dengan penelitian (Styowati dan Yushita 2018). menunjukan bahwa sanksi pajak memiliki pngaruh yang positif dan signitfikan terhadap Kepatuhn Wajib Pajak.

\section{Upaya dalam Meningkatkan Kepatuhan Wajib Pajak PBB di Kecamatan Cidahu Kabupaten Sukabumi}

Selain dari wajib pajk yang menbandel, serta dalam hal penyampaian SPPT pajak PBB di Kecamatan Cidahu sering kali timbul kendala karena tidak semua wajib pajak menempati objek pajaknya sehingga berdampak pada tidak patuhnya dan menghambatnya penerimaan pajak PBB. Dalam rangka meningikatkan kepatuhan wajb pajak, petugas pajak Kecamatan Cidahu melakukan upaya dengan cara meminta dan mendata alamat setiap wajib pajak yng tidak menempati objek pajaknya. Sehingga pada saat setiap dilakukan pemungutan PBB, petugas pajak bisa datang dan menagih langsung ke alamat wajib pajak atau dengan mengirimkan/menyampaikan SPPT kpada wajib pajaak yang bersangkutan. Mutasi/perpindahan yang tidak melapor akan menyulitkan aparat dalam menyampaikan SPPT PBB sehingga memerlukan banyak waktu, untuk itu keterlibatan aparat desa atau kelurahan sangat dibutuhkan sebagai upaya dallam meningkatkan kpatuhan wajib pajak 
karena lebih mengetahui asal-usul objek pajak yang ada di daerahnya.

\section{KESIMPULAN DAN SARAN \\ Simpulan}

1. Penyuluhan pajak, SPPT, dan sanksi pajak secara simultan berpengarruh positif dan signifikn terhadap kepatuahan wajib pajak PBB pada Kecamatan Cidahu Kabupaten Sukabumi.

2. Penyuluhan pajak dan sanksi pajak secara parsial berpengruh positif dan signifikan terhadap kepatuhan wajb pajak PBB, akan tetapi pada variabel SPPT menunjukan hasil yang berbeda secara parsial yaitu berpengaruh negatif dan signifikan trhadap kepatuhan wajib Pjak PBB pada Kecamaatn Cidahu Kabupaten Sukabmi.

3. Upaya yang dilakukan dalam meningtkatkan kepatuhan wajb pajak di Kecamatan Cidahu dengan cara petugas pajak meminta dan mendata alamat setiap wajib pajak yanng tidak menempati objek pajaknya, apabila diketahui ada wajib pajak yng tidak menempati objek pajaknya. Sehingga pada saat setiap dilakukan pemungutan pajak petugas pajak bisa menagihnya langsung ketempat alamat tersebut atau dengan mengirimkan SPPT ke alamat wajib pajak yang bersangkutan. Keterlibatan aparat desa atau kelurahan sangat dibutuhkan sebagai upaya dalam meningikatkan kepatuhn wajib pajak apabila adanya mutasi/perpindahan objek pajak yang tidak melapor.

\section{Saran}

1. Bagi petugas pajak, untuk lebih aktif dalam melakukan pengawasan dan penyuluhan perpajakan di daerah dalam rangka meningkatkan kepatuhan wajib pajak, karena mayoritas wajib pajak belum memahami tentang perpajakan. Semakin baik dan menarik penyuluhan yang diberikan oleh petugas pajak maka tingkat kepatuhan wajib pajak dalam membayar PBB juga akan meningkat. Petugas pajak harus disiplin dalam menjalankan tugasnya, yaitu agar tepat waktu dalam mendistribusikan SPPT kepada wajib pajak untuk meminimalisir terjadinya tunggakan pajak. Diperlukan sanksi yang tegas dan jelas untuk memberikan efek jera pada wajib pajak yang melakukan pelanggaran pajak atau tidak memenuhi kewajiban perpajakannya.

2. Bagi peneliti selanjutnya, diharapkan untuk menambah variabel penelitian, agar dapat diketahui adanya variabel lain yang dapat mempengaruhi kepatuhan wajib pajak. Serta disarankan untuk melengkapi metode survei dengan wawancara untuk meningkatkan kualitas jawaban responden.

\section{DAFTAR PUSTAKA}

Arifin, S. B., \& Nasution, A. A. (2017). Pengaruh Kualitas Pelayanan dan Sanksi Perpajakan Terhadap kepatuhan Wajib Pajak Badan di KPP Pratama Medan belawan. JURNAL AKUNTANSI DAN BISNIS: Jurnal Program Studi Akuntansi, 3(2).

Dewi, N. K. E. S., Diatmika, I. P. G., AK, S., Si, M., \& Yasa, I. N. P. (2018). Pengaruh Penerimaan Surat Pemberitahuan Pajak Terutang (Sppt), Pendapatan Wajib Pajak, Dan Kesadaran Wajib Pajak Terhadap Kepatuhan Wajib Pajak Bumi Dan Bangunan Perdesaan Dan Perkotaan (Pbb-P2) Di Kabupaten Buleleng. JIMAT (Jurnal Ilmiah Mahasiswa Akuntansi) Undiksha, 8(2).

Dewi, D. C., \& Zulfikar, D. S. (2018). Analisis Faktor-Faktor Yang Mempengaruhi Kepatuhan Wajib Pajak Bumi Dan Bangunan Di Kabupaten Wonogiri (Doctoral dissertation, Universitas Muhammadiyah Surakarta).

Kusuma, I. P. T. (2015). Faktor-faktor yang Mempengaruhi Kepatuhan Wajib Pajak Dalam Membayar Pajak Bumi dan Bangunan. Jurnal Penelitian Ekonomi dan Bisnis, 1(2), 1-20.

Kusuma, I. C., \& Rachmini, R. (2018). Analisis Kinerja Koperasi Agro Humaniora Pada Aspek Produktifitas Berdasarkan Peraturan Menteri 
Negara Koperasi Dan Usaha Kecil Dan Menengah Republik Indonesia Nomor: 06/PER/M.

KUKM/V/2006. JURNAL AKUNIDA, 2(2), 27-40.

Marchori, F. (2018). Pengaruh Kesadaran Wajib Pajak, Pelayanan Fiskus, Dan Sanksi Pajak Terhadap Kepatuhan Wajib Pajak Orang Pribadi Yang Melakukan Usaha Kecil Menengah (Studi Empiris pada Kantor Pelayanan Penyuluhan dan Konsultasi Perpajakan Kota Sungai Penuh). Jurnal Akuntansi, 6(3).

Mardismo, 2016, Perpajakan, Edisi Terbaru, Andi, Yogyakarta.

Menteri Keuangan No. 192/PMK.03/2007 Tentang Kepatuhan Wajib Pajak.

Nafiah, Z., \& Warno, W. (2018). Pengaruh Sanksi Pajak, Kesadaran Wajib Pajak, Dan Kualitas Pelayanan Pajak Terhadap Kepatuhan Wajib Pajak Dalam Membayar Pajak Bumi Dan Bangunan (Study Kasus Pada Kecamatan Candisari Kota Semarang Tahun 2016). Jurnal STIE Semarang, 10(1), 86-105.

Rahajeng, D. C. (2017). Pengaruh Pemahaman Perpajakan, Persepsi Sanksi Pajak Dan Kualitas Pelayanan Perpajakan Terhadap Kepatuhan Wajib Pajak Dalam Penerapan Self Assessment System (Doctoral dissertation, STIE PERBANAS SURABAYA).

Rismawati, Sudirman dan Amirudin, Antong, 2015, Perpajakan Pendekatan Teori dan Praktek, Empat Dua Media, Malang.

Septarini, D. F. (2015). Pengaruh Pelayanan, Sanksi, Dan Kesadaran Wajib Pajak Terhadap Kepatuhan Wajib Pajak Orang Pribadi Di Kpp Pratama
Merauke. Jurnal Ilmu Ekonomi \& Sosial, 6(1), 29-43.

Setyowati, Y., \& Yushita, A. N. (2017). Pengaruh Pengetahuan Perpajakan, Sanksi Pajak Dan Kesadaran Wajib Pajak Terhadap Kepatuhan Wajib Pajak Orang Pribadi Dalam Membayar Pajak Bumi Dan Bangunan Di Desa Kalidengen, Kecamatan Temon, Kabupaten Kulon Progo Tahun 2014. Jurnal Profita: Kajian Ilmu Akuntansi, 5(8).

Sugiyono, 2015, Cara Mudah Menyusun Skripsi, Tesis dan Disertasi, Alfabeta, Bandung

Undang-Undang Dasar 1945 Pasal 23 ayat 2 Tentang Dasar hukum pajak.

Wuryanto, L., Sadiati, U., \& Afif, M. N. (2019). $\quad$ Faktor-Faktor Yang Mempengaruhi Kepatuhan Wajib Pajak Dalam Membayar Pajak Kendaraan Bermotor. JURNAL AKUNIDA, 5(2), 1531.

Warizal, W., Nirwanti, N., \& Setiawan, A. B. (2019). Return On Invesment (Roi), Economic Value Added (Eva), Dan Return Saham: Studi Empiris Pada Perusahaan Lq45. JURNAL AKUNIDA, 5(2), 47-58.

Yakin, K. A., \& Amrulloh, R. (2018). Identifikasi Faktor-Faktor Yang Mempengaruhi Kepatuhan Subyek Pajak Dalam Melakukan Pembayaran Pajak Bumi Dan Bangunan Di Kecamatan Tulangan. Identifikasi Faktor Faktor Yang Mempengaruhi Kepatuhan Subyek Pajak Dalam Melakukan Pembayaran Pajak Bumi Dan Bangunan Di Kecamatan Tulangan. 